\title{
Heparin-binding Peptides as Novel Therapies to Stop SARS-CoV-2 Cellular Entry and Infection
}

\author{
Omid Tavassoly, Farinaz Safavi, and Iman Tavassoly ${ }^{1}$ \\ Department of Chemistry, Simon Fraser University, Burnaby, British Columbia, Canada (O.T.); Neuroimmunology and \\ Neurovirology Branch, National Institute of Neurologic Disorders and Stroke, National Institutes of Health, Bethesda, Maryland \\ (F.S.); and Mount Sinai Institute for Systems Biomedicine, Icahn School of Medicine at Mount Sinai, New York, New York (I.T.)
}

Received June 20, 2020; accepted August 27, 2020

\section{ABSTRACT}

Heparan sulfate proteoglycans (HSPGs) are cell surface receptors that are involved in the cellular uptake of pathologic amyloid proteins and viruses, including the novel coronavirus; severe acute respiratory syndrome coronavirus 2 (SARS-CoV-2). Heparin and heparan sulfate antagonize the binding of these pathogens to HSPGs and stop their cellular internalization, but the anticoagulant effect of these agents has been limiting their use in the treatment of viral infections. Heparin-binding peptides (HBPs) are suitable nonanticoagulant agents that are capable of antagonizing binding of heparin-binding pathogens to HSPGs. Here, we review and discuss the use of HBPs as viral uptake inhibitors and will address their benefits and limitations to treat viral infections. Furthermore, we will discuss a variant of these peptides that is in the clinic and can be considered as a novel therapy in coronavirus disease 2019 (COVID-19) infection.

\section{SIGNIFICANCE STATEMENT}

The need to discover treatment modalities for COVID-19 is a necessity, and therapeutic interventions such as heparinbinding peptides (HBPs), which are used for other cases, can be beneficial based on their mechanisms of actions. In this paper, we have discussed the application of HBPs as viral uptake inhibitors in COVID-19 and explained possible mechanisms of actions and the therapeutic effects.

\section{Introduction}

Heparin binding is a common feature in some viruses and all pathologic amyloid proteins. These pathogens use this characteristic to bind heparan sulfate proteoglycans (HSPGs) on host cells and internalize into the cells. Thus, heparin and heparan sulfate therapy stop the binding of these pathogens to HSPGs and reduce the level of infectivity (Compton et al., 1993; Giroglou et al., 2001; de Haan et al., 2008; Leistner et al., 2008; Sandwall et al., 2010; Bourgault et al., 2011; Martin and Ramirez-Alvarado, 2011; Noborn et al., 2011, 2012; Donalisio et al., 2012; Holmes et al., 2013; Cagno et al., 2014; Milewska et al., 2014; Dogra et al., 2015; Xu et al., 2015; Pitt et al., 2016; Ghezzi et al., 2017; Kim et al., 2017; Tan et al., 2017; Rauch et al., 2018; Hudák et al., 2019; Jackson et al., 2019; Tang et al., 2020). Recent studies have shown that receptor-binding

O.T. is supported by a grant from the W. Garfield Weston Foundation (Weston Brain Institute) [Grant RR171033]. This work was partly supported by the Intramural Research Program of the National Institute of Neurological Disorder and Stroke/ National Institutes of Health [Grant NS003031] (to F.S.).

${ }^{1}$ Current affiliation: C2i Genomics, New York, New York.

https://doi.org/10.1124/molpharm.120.000098. domain which is located within the $\mathrm{S} 1$ subunit of spike glycoprotein of the novel SARS-CoV-2 virus, also binds to heparin (C. Mycroft-Wes et al., preprint, DOI: https://doi.org/ 10.1101/2020.02.29.971093), and administration of low-molecular-weight heparin reduces mortality in severe COVID-19 sepsis with sepsis-induced coagulopathy (SIC) score $\geq 4$ or D-dimer > sixfold of the upper limit of normal (Tang et al., 2020). Sepsis in severe cases of COVID-19 induces coagulopathy (SIC) or elevated D-dimer (Connors and Levy, 2020; Langer et al, 2020; Tang et al., 2020; The Lancet Haematology, 2020). Although associated with an increased risk of bleeding, heparin therapy resulted in no survival benefits in the overall sepsis population, and the beneficial effects on mortality were observed only in the severe COVID-19 cases with extreme SIC score and very high level of D-dimer. Despite this minor benefit in a subgroup of severe COVID-19 to control hypercoagulation, heparin therapy is not recommended for mild COVID-19 cases (nonsepsis cases), which are almost $70 \%$ of reported patients with COVID-19, as well as control population to prevent viral entry via HSPG-mediated endocytosis and subsequent viral replication (Hirsh et al., 2001; Crowther

ABBREVIATIONS: AL, light chain; COVID-19, coronavirus disease 2019; CRM-197, cross-reacting material-197; HB-EGF, heparin-binding EGF-like growth factor; HBP, heparin-binding peptide; HS, heparan sulfate; HSPG, heparan sulfate proteoglycan; P5, peptide number 5; (P5R) main variant of P5 with a D-form of P5 with all lysines substituted with arginine (R); PK/PD, pharmacokinetics/pharmacodynamics; PET, positron emission tomography; SARS-CoV-2, severe acute respiratory syndrome coronavirus 2; SIC, sepsis-induced coagulopathy; TTR, transthyretin. 
and Warkentin, 2008; Umemura et al., 2016; Nishida et al., 2018; Tang et al., 2020). On the other hand, heparin-binding peptides (HBPs) can antagonize the binding of heparinbinding pathogens to HSPGs. A group of these synthetic peptides (Peptide number 5 (P5) family of peptides) was developed as positron emission tomography (PET) imaging agents to detect extracellular amyloid depositions in the peripheral nervous system of mice models of amyloidosis (Wall et al., 2011, 2012, 2013a, 2015, 2017, 2019; Martin et al., 2013, 2014, 2016; Kennel et al., 2016a; Stuckey et al., 2020). Some of these P5 families of peptides (Table 1) have been already tested in cell lines and preclinical animal models to evaluate their ability to control the infection of herpes viruses (Dogra et al., 2015; Pitt et al., 2016; Jackson et al., 2019). The results of these studies showed that these peptides possess a strong inhibitory effect in cell cultures but were not efficient in animal models of viral infection. All the above reports are based on the preventive (prophylactic) effect of these compounds in which administration of the peptide in cell cultures or animal models happened before induction of infection (Dogra et al., 2015; Pitt et al., 2016; Jackson et al., 2019). This strong inhibitory effect in cell cultures is due to the binding of HBPs to cell surface HSPGs, which antagonizes the interaction of viruses with HSPGs and subsequently reduces viral particle uptake (Fig. 1). However, in animal models of infection generated by intraperitoneal inoculation of viruses, the infection quickly spreads through the whole body and also might cause sepsis (Murando et al., 2019). Thus, upon infection induction, viruses enter the cytoplasm of cells where the peptide therapeutics (Table 1) cannot reach to neutralize them. In general, the infection starts when viruses hijack cellular endocytosis pathways such as HSPG-mediated endocytosis to enter cells and use the endosomal pathway to travel through the cytoplasm and reach the nucleus to initiate their replication and infection. To avoid the host degradation system, viruses can escape endosomes and enter cytoplasm before the fusion of endosomes with the lysosome (Fig. 2A) (Greber and Way, 2006; Xiao and Samulski, 2012; Staring et al., 2018). Accordingly, peptide-based therapeutics, including HBPs, also enter cells through similar endocytic pathways, but they cannot escape the endosomal/lysosomal system and finally will be sorted to the lysosome for degradation (Fig. 2B). Therefore, they are not effective enough to suppress cytoplasmic viral particles, leading to the continuation of viral exit from infected cells to infect neighboring cells and cell-tocell spread of infection. We believe this limitation might be the reason for unsuccessful outcomes in testing these peptides in in vivo models of viral infection. Here, we address this limitation by proposing conjugation of these peptides with a nontoxic carrier protein that escapes endosomes and is able to transfer HBPs to the cytoplasm, where they target and neutralize cytoplasmic viruses to stop cell-to-cell spread of infection (Fig. 2C) (De Boer and Gaillard, 2007; Kakimoto et al., 2009). Furthermore, Tavassoly et al. (2020) recently showed that these amyloid binding HBPs reduce $\alpha$-synucleinamyloid fibril uptake in cell cultures, which potentially confirms their ability to stop the first stage of pathogen entry into cells by antagonizing docking of pathogenic particles to HSPGs. Moreover, our unpublished results (O.T.) showed that other synthetic (HBP-I: GKKQRFRHRNRKG) and natural HBPs [heparin-binding EGF-like growth factor (HB-EGF) and cross-reacting material-197 (CRM-197)] can block cellular

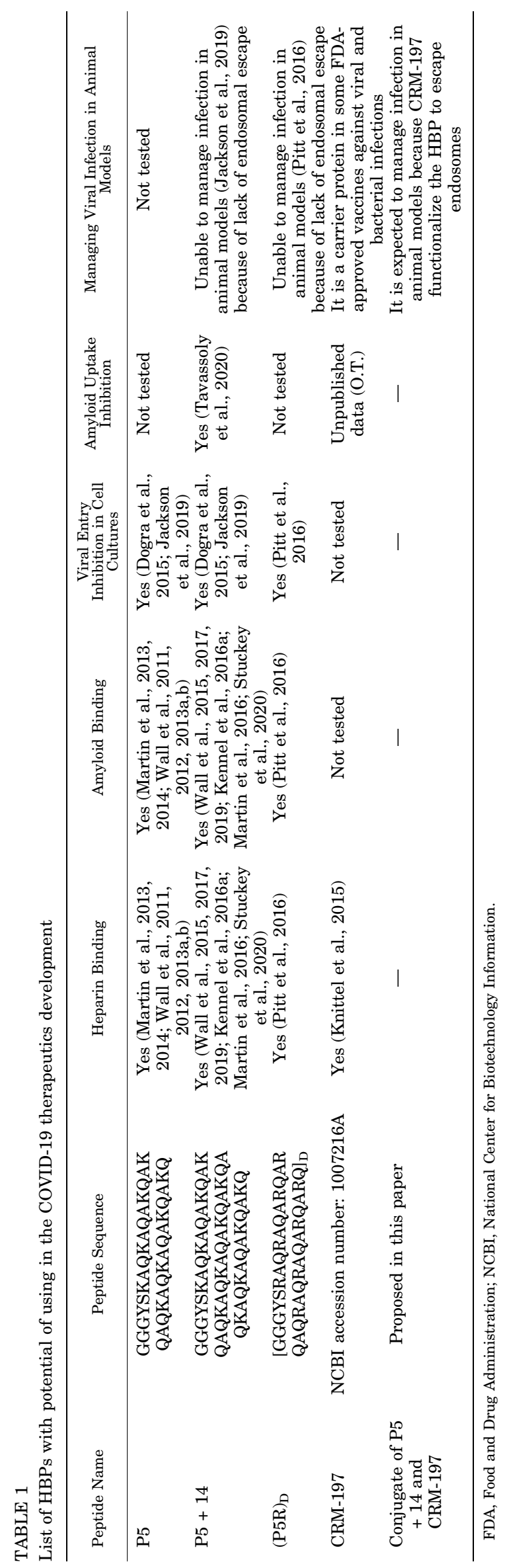


A

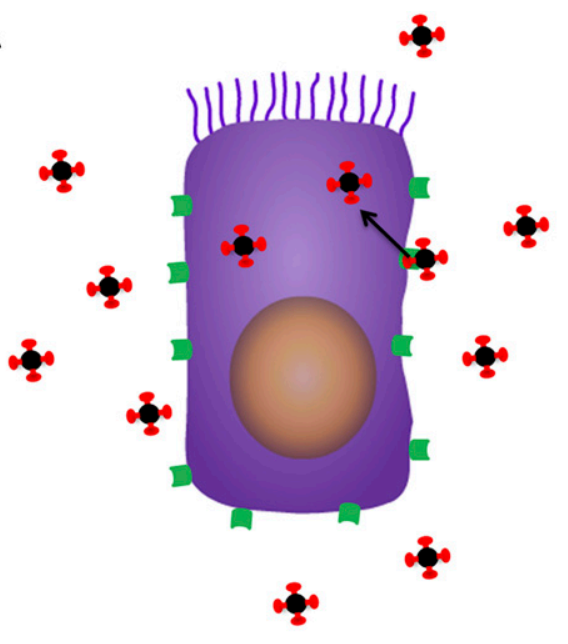

HSPG
B

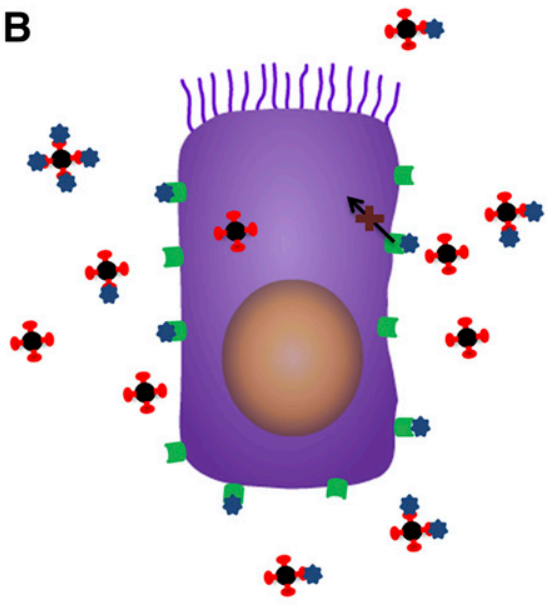

Fig. 1. HBPs mode of action. (A) Heparinbinding viruses dock to their cellular receptors (HSPGs) and hijack HSPG-mediated endocytosis to enter cells. (B) Pretreatment of cells with HBPs or viral incubation with HBPs results in neutralizing HSPGs or viruses with HBPs, respectively. This neutralization antagonizes the virus-HSPG binding and leads to a reduction in the level of viral uptake. internalization of $\alpha$-synuclein-amyloid fibrils as well. HB-EGF is a growth factor that activates the epithermal growth factor receptor and has neuroprotective effects (Gaviglio et al., 2017; Zhou et al., 2017). CRM-197 is the nontoxic mutant of diphtheria toxin and is used as a carrier protein in several approved vaccines, such as HibTITER (Haemophilus influenzae type b-associated diseases), Prevnar (pneumococcal diseases), and Menveo (meningococcal diseases) (Shinefield, 2010; Möginger et al., 2016). A missense mutation that substitutes glycine in position 52 to glutamic acid converts diphtheria toxin to a nontoxic carrier protein (Giannini et al., 1984; Malito et al., 2012). Interestingly, it has been shown that CRM-197 has four heparin-binding domains (Knittel et al., 2015), which potentially can act as an antagonizing agent to stop the binding of heparin-binding pathogens into the cell surface HSPGs. Furthermore, this carrier protein is capable of escaping the endosomal pathway and transferring its cargo into the cytoplasm (De Boer and Gaillard, 2007; Kakimoto et al., 2009). Thus, conjugation of available HBPs with CRM197 might be a suitable engineering strategy to functionalize and enable them to escape endosomes and neutralize cytoplasmic viral particles (De Boer and Gaillard, 2007; Kakimoto et al., 2009). This engineered therapeutic agent can be used in preclinical models of infection as well as clinical studies because of its favorable pharmacokinetic/pharmacodynamic (PK/PD) properties that even facilitate its entry into the central nervous system (Gaillard et al., 2005; Wang et al., 2011) to neutralize brain infection and reduce subsequent neuropathology. In this perspective, we emphasize on targeting SARS-CoV-2 heparin binding and review the current available HBPs, which are already tested in the preclinical animal models of amyloidosis and viral infections. We finally
A

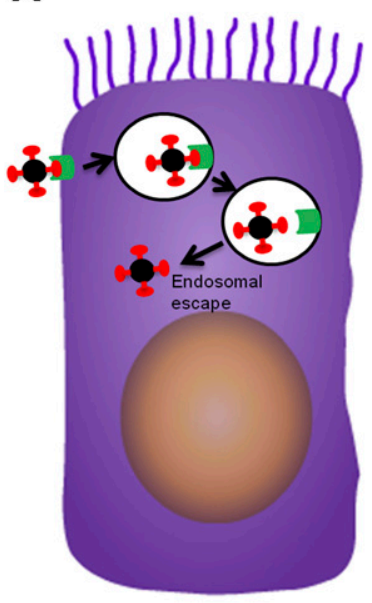

B

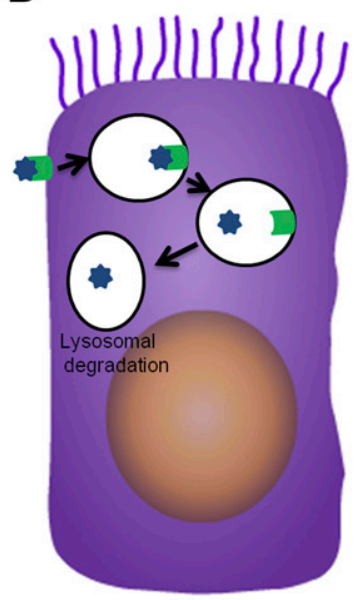

C

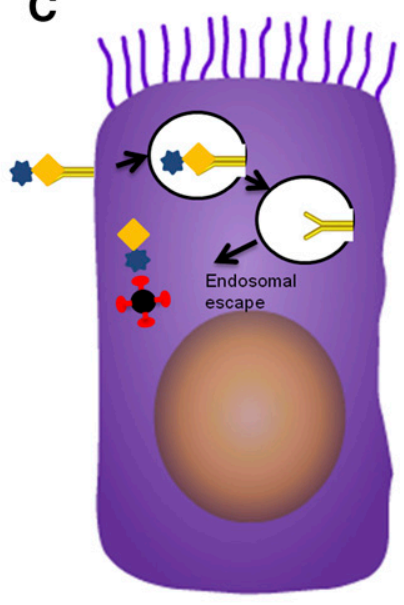

Fig. 2. Cellular trafficking of viruses and HBPs. (A) Upon HSPG-mediated endocytosis, viruses enter the endosomal pathway but escape from endosomes to enter the cytoplasm and reach to the nucleus to start replication or exit from cells to transfect neighboring cells. (B) HBPs also internalize by HSPG-mediated endocytosis and enter the endosomal-lysosomal system, but they are not capable of escaping endosomes. Thus, HBPs will be sorted to the lysosome for degradation and cannot reach cytoplasmic viruses. (C) Conjugates of HBP-CRM-197 use CRM-197 receptor to enter the endosomal pathway, but CRM-197 can escape endosomes before reaching to lysosomes for degradation. 
propose an engineering strategy to design a novel conjugate therapeutic agent that might address the limitation of current HBPs in animal models of infection. This approach can potentially target cellular entry and propagation of viruses and amyloid proteins and can be considered as a possible therapy for COVID-19.

\section{Heparan Sulfate Proteoglycans as COVID-19 Receptor}

HSPGs are cell membrane glycoproteins composed of proteins covalently attached with heparan sulfate (HS) chains. HS is a linear polysaccharide composed of sulfated repeats of different disaccharide blocks (Sarrazine et al., 2011; Christianson and Belting, 2014). These extracellular polysaccharides bind to different ligands and serve as a cell surface docking site or receptor for the attached ligands. It has been shown that a variety of viruses and pathologic amyloid proteins bind to HS and internalize into host cells by hijacking the HSPGs-mediated endocytosis pathway (Compton et al., 1993; Giroglou et al., 2001; De Haan et al., 2008; Leistner et al., 2008; Sandwall et al., 2010; Bourgault et al., 2011; Martin and Ramirez-Alvarado, 2011; Noborn et al., 2011, 2012; Donalisio et al., 2012; Holmes et al., 2013; Cagno et al., 2014; Milewska et al., 2014; Dogra et al., 2015; Xu et al., 2015; Pitt et al., 2016; Ghezzi et al., 2017; Kim et al., 2017; Tan et al., 2017; Rauch et al., 2018; Hudák et al., 2019; Jackson et al., 2019; Tang et al., 2020). Examples of viruses that use HSPG to infect cells are cytomegalovirus (Compton et al., 1993; Jackson et al., 2019), respiratory syncytial virus (Donalisio et al., 2012; Cagno et al., 2014; Johnson et al., 2015), human papillomavirus (Giroglou et al., 2001; Buck et al, 2013), hepatitis-C virus (Xu et al., 2015), hepatitis-B virus (Leistner et al., 2008), Zika virus (Ghezzi et al., 2017; Kim et al., 2017; Tan et al., 2017), and coronavirus (De Haan et al., 2008; Milewska et al., 2014). In the case of pathologic amyloid-related proteins, the heparin-binding property and prion-like cell-to-cell propagation are characterized for both peripheral and central nervous system-related proteins, including prions (Schonberger et al., 2003; Horonchik et al., 2005), tau (Holmes et al., 2013; Rauch et al., 2018), $\alpha$-synuclein (Holmes et al., 2013; Hudák et al., 2019), amyloid- $\beta$ (Sandwall et al., 2010), serum amyloid A protein (Noborn et al., 2012; Lu et al., 2014), light chain (AL) (Martin and Ramirez-Alvarado, 2011; Blancas-Mejía et al., 2015), and transthyretin (TTR) (Bourgault et al., 2011; Noborn et al., 2011). In all these viral and amyloid pathogens, exogenous heparin or HS antagonizes cellular endocytosis and ameliorates subsequent infections and pathologies. Recently, SARS-CoV-2 was also found to be a heparin-binding virus with several potential heparin-binding sites located within the spike S1 protein (C. Mycroft-Wes et al., preprint, DOI: https://doi.org/10.1101/2020.02.29.971093). Furthermore, heparin treatment in patients with severe COVID-19 shows promising results to control the disease mortality (Tang et al., 2020).

Thus, HBPs are potentially capable of stopping cellular entry and infection of SARS-CoV-2 in a way like the other heparin-binding viruses. Because one variant of these HBPs is already in the clinical trials (Wall et al., 2019; Stuckey et al., 2020), it has the potential to be applied as alternative therapeutics for COVID-19.

\section{Targeting HSPG Binding with HBPs}

In this paper, we focus on a class of HBPs developed initially to bind peripheral amyloid structures (Wall et al., 2011, 2012, 2013a, 2015, 2017, 2019; Martin et al., 2013, 2014, 2016; Kennel et al., 2016a; Stuckey et al., 2020) but was found to act as endocytosis inhibitors to stop cellular uptake of herpes viruses (Dogra et al., 2015; Pitt et al., 2016; Jackson et al., 2019) and $\alpha$-synuclein fibrils (Tavassoly et al., 2020). The lead peptide of this group, P5, was characterized as the most potent peptide among a series of seven heparin-binding peptides (P1P7). The P5 peptide has high affinity for heparin as well as favorable tissue biodistribution and amyloid binding. Its function was evaluated by small-animal single photon emission tomography imaging in an AA amyloidosis mouse model as well as microautoradiography in tissue sections. This 31-residue peptide, which contains a heptad repeat of amino acids (-KAQKAQA-), reacts with amyloid structures of serum amyloid A protein, AL, TTR, and amyloid- $\beta$ in tissue sections from AA amyloidosis, AL amyloidosis, TTR amyloidosis, and Alzheimer disease, respectively (Wall et al., 2011, 2012, 2013a,b; Martin et al., 2013, 2014; Kennel et al., 2016b). Two main variants of this peptide were generated to improve its PK/PD properties, including biodistribution, fast clearance in normal tissues, and higher amyloid binding affinity. In 2015, an extended variant of P5 was generated by adding 14 more residues (including four additional lysine residues) to the P5 peptide to improve its heparin-binding affinity and subsequently to enhance the amyloid-binding properties (Wall et al., 2015). The resulted peptide, P5 +14 , possesses more favorable binding to synthetic amyloid structures, tissuederived amyloids, and improved PK/PD properties in binding to tissue amyloid deposits in mice models of AA amyloidosis compared with original P5 peptide (Wall et al., 2015, 2017; Kennel et al., 2016; Martin et al., 2016; Beierle et al., 2017). Phase I trial studies of P5 + 14 peptide have shown promising results in the detection of amyloid deposits in multiple organs using a radiolabeled analog of this peptide in PET imaging of systemic amyloidosis patients (Wall et al., 2019; Stuckey et al., 2020). Another main variant of P5 is a D-form of P5 with all lysines substituted with arginine $(\mathrm{R}),(\mathrm{P} 5 \mathrm{R})_{\mathrm{D}}$. The resulted peptide has more heparin-binding activity as well as a higher half-life in animal studies (Pitt et al., 2016).

Additionally, these novel peptides can also bind to heparinbinding viruses, such as herpes simplex viruses and human cytomegalovirus, that antagonize viral uptake and subsequently reduce viral infection in cells exposed to these viruses. In cell culture studies, the P5 + 14 peptide has shown the most favorable efficacy in diminishing the cellular infection $(90 \%)$ compared with P5 (53\%) and P5R (75\%) (Dogra et al., 2015). Furthermore, recently, Tavassoly et al. (2020) showed that pretreatment of cells with P $5+14$ peptide reduces the level of $\alpha$-synuclein-fibrils uptake. $\alpha$-Synuclein is a misfolded protein that forms heparin-binding fibrils in the Parkinson disease brain. These fibrils can propagate neuron-toneuron in a prion-like manner and spread the pathology throughout the brain, similar to viruses. Thus, stopping cellular uptake and propagation of these pathologic fibrils is a target in Parkinson's disease therapy development (Luk et al., 2012a,b; Tavassoly et al., 2018, 2020). In another study, P5R and its D-form analog, $(\mathrm{P} 5 \mathrm{R})_{\mathrm{D}}$, were tested in cell cultures infected with human cytomegalovirus. The results showed that 
$(\mathrm{P} 5 \mathrm{R})_{\mathrm{D}}$ had more antiviral activity than the original L-form peptide. Pretreatment of cells with this peptide led to a $90 \%$ reduction in the infection (Pitt et al., 2016). Despite the ability of these peptides to block virus entry in vitro, they were unable to reduce infectivity in vivo significantly (Pitt et al., 2016; Jackson et al., 2019). This unfavorable PD in animal models might be due to PK barriers, such as the lack of endosomal escape ability of these peptides to reach cytoplasmic viruses that already escaped the endosomal trafficking pathway and survived from lysosomal degradation (Greber and Way, 2006; Xiao and Samulski, 2012; Staring et al., 2018). HBPs upon internalization enter the endosomal pathway and are finally degraded by lysosomes (Fig. 2B), whereas viruses can escape this trafficking pathway and enter cytoplasm (Fig. 2A) to 1) reach nucleus where they start replication and/or 2) exit cells to transfect neighboring cells (Greber and Way, 2006; Xiao and Samulski, 2012; Staring et al., 2018). Therefore, there would be insufficient target engagement for HBPs in animal models of infection. Here, we suggest the use of an approved vaccine carrier protein like CRM-197, a nontoxic mutant of diphtheria toxin, which itself is a heparin-binding protein and can mimic viral pathogens and escape from the endosomal pathway to enter cytoplasm (De Boer and Gaillard, 2007; Kakimoto et al., 2009). Therefore, a molecule containing conjugates of P5 +14 peptide with CRM-197 can specifically enter cells by hijacking CRM-197 receptor, pro-HB-EGF, and subsequently escape endosomes to enter cytoplasm, where they bind and neutralize the viruses (Fig. 2C), stopping their replication in the nucleus and subsequent cell-to-cell propagation.

\section{Molecular Interaction Studies: HBPs Docking to SARS-CoV-2 Spike Protein S1}

The HDOCK server (Yan et al., 2020) was used to estimate potential interactions between HBPs (P5 + 14 and CRM-197) and SARS-CoV-2 spike protein S1. This server generates 100 theoretical models of possible protein-protein (peptide) interactions and scores them based on docking energy (Yan et al., 2020). An analog of P5 + 14 in which all lysine residues were
A
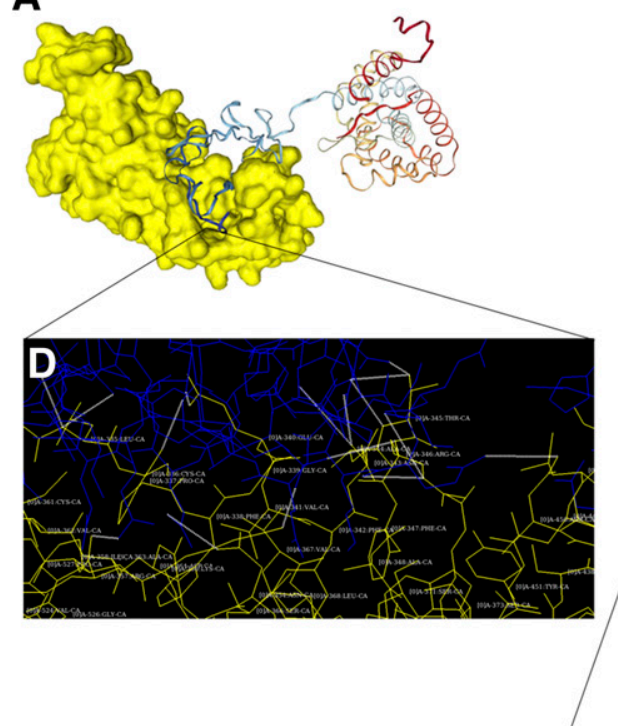

B
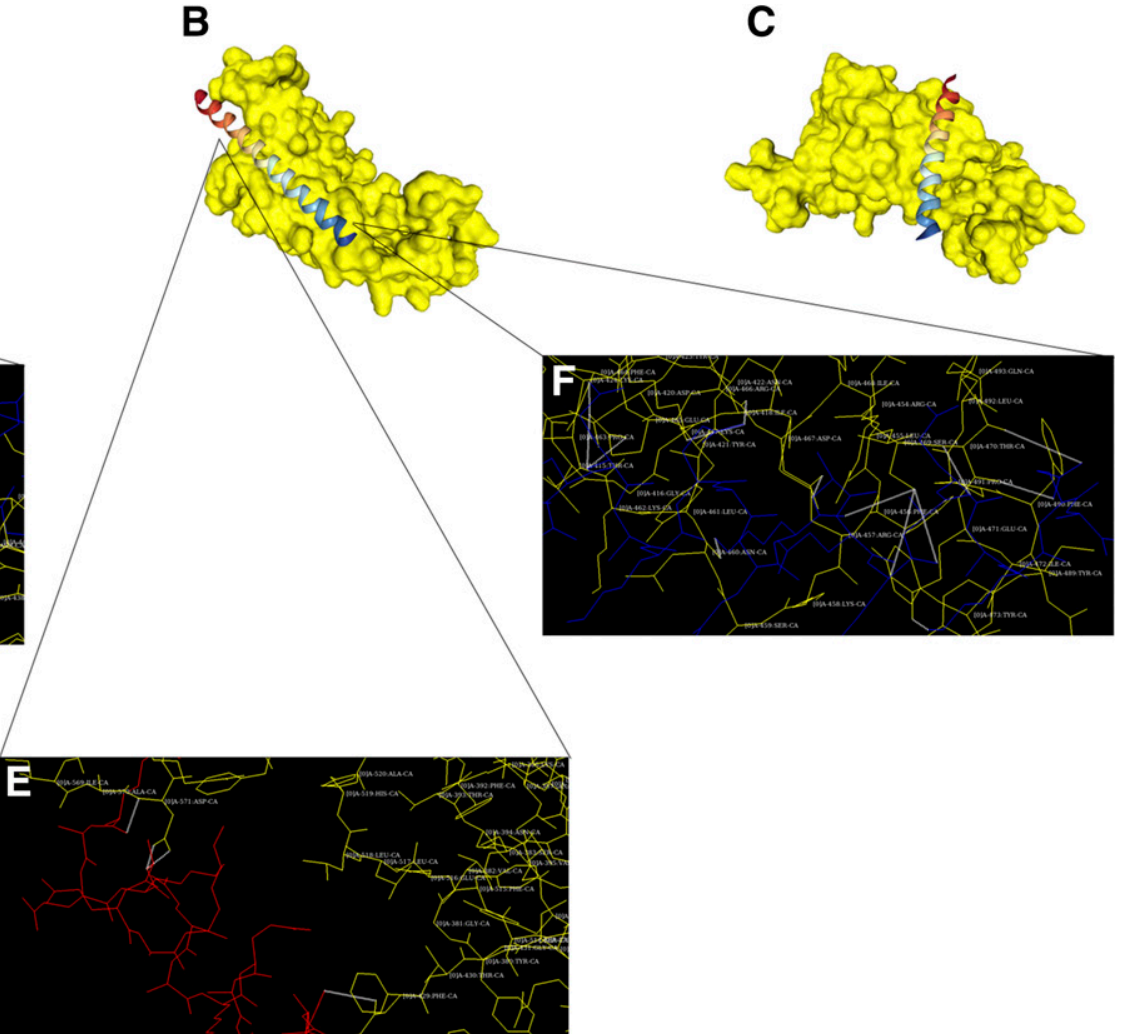

Fig. 3. HBPs docking to SARS-CoV-2 spike protein S1. (A) Docking model showing the interaction of heparin-binding domains of spike protein S1 (yellow) and CRM-197 (rainbow). (B) Docking model showing the interaction of P5 + 14 peptide (rainbow) with the heparin-binding domain of spike protein S1 (yellow). (C) Docking model showing the interaction of control peptide (rainbow) with the heparin-binding domain of spike protein S1 (yellow). (D) Detailed docking model of results in (A) showing molecular interactions between spike protein S1 (yellow) and CRM-197 (blue). Electrostatic interactions between residues are shown as white dotted lines. Protein spike S1 residues involved in the interaction are shown. Binding involves interaction between Asn-354, Arg-357, Lys-356, Leu-335, Leu-335, Cys-336, Asn-343, Asn-343, Arg-346, Arg-346, Asn-450, Arg-346, Glu-340, Thr-345, Thr-345, and Thr-345 residues from spike protein S1 and Glu-249, Gln-252, Glu-248, Thr-256, Lys-264, Gly-268, Pro-271, Asn-270, Glu-241, Glu-240, Glu-241, Glu-248, His-251, Ala-276, Ala-276, and Asn-277 residues from CRM-197. (E) Detailed docking model of results in (B) showing molecular interactions between spike protein S1 (yellow) and N-terminus of P5 + 14 (red). Electrostatic interactions between residues are shown as white dotted lines. Protein spike S1 residues involved in the interaction are shown. Binding involves interaction between Asp-428, Asp-571, and Asp-571 residues from spike protein S1 and Lys-20, Ala-10, and Lys-6 residues from P5 + 14 peptide. (F) Detailed docking model of results in (B) showing molecular interaction between spike protein S1 (yellow) and C-terminus of P5 + 14 (blue). Electrostatic interactions between residues are shown as white dotted lines. Protein spike S1 residues involved in the interaction are shown. Binding involves interaction between Thr-470, Thr-470, Ser-469, Ser-469, Ser-469, Glu-471, Asp467, Asn-460, Arg-466, Glu-465, and Glu-465 residues from spike protein S1 and Gln-42, Ala-35, Lys-37, Ala-38, Lys-34, Ala-38, Ala-35, Lys-34, Gln-31, Gln-31 and Gln-28 from P5 + 14 peptide. 
substituted to glutamic acid was used as docking control because of its negative net charge, which repulses its interaction with heparin or heparin-binding domains. The structure of P5 + 14 and control peptide was modeled using SWISS-MODEL, which is a protein structure homologymodeling server (Waterhouse et al., 2018). Moreover, the structure of the CRM-197 heparin-binding domain (residues 165-467) (Knittel et al., 2015) was extracted from the reported crystal structure for CRM-197 (PDB \#5I82) (Mishra et al., 2018). Furthermore, the structure of the proposed heparin-binding domain for SARS-CoV-2 spike protein S1 (residues 330-583) was extracted from a modeled structure (QHD43416.pdb), which is generated using C-I-TASSER pipeline (Huang et al., 2020; Zhang et al., 2020). Docking results (Fig. 3, A and $\mathrm{B}$ ) showed that interaction of spike protein S1 with CRM-197 (docking energy score: -297.90) is more favorable than its interaction with P5 + 14 (docking energy score: -207.93), which might be due to differences in structure and size that affect their interaction with spike protein S1. Furthermore, interaction of control peptide with spike protein S1 was nonspecific (docking energy score: -178.69), and its binding site was located on the opposite side of CRM-197 and P5 + 14 binding sites on protein spike S1 structure (Fig. 3C). The stronger interaction for CRM-197 might be because it possesses four heparin-binding sites (Knittel et al., 2015), whereas P5 + 14 is composed of just one heparin-binding domain. In addition, although binding sites for CRM-197 and P4 + 14 were different, they were located nearby and on the same side of spike protein S1 structure. Molecular interactions between spike protein S1 and HBPs (CRM-197 and P5 + 14) were determined using "Hex 8.0.0" software (Fig. 3, D and E) (Ritchie, 2003; Mustard and Ritchie, 2005). Thus, this suggests that binding of CRM197 and P5 + 14 peptides with spike protein S1 is noncompetitive and conjugation of these HBPs might increase the efficacy in stopping SARS-Cov-2 infection (Fig. 3, A and B).

\section{Discussion and Conclusion}

The emerging COVID-19 pandemic caused an unexpected and large number of infections leading to significant mortality globally. Because of mandatory quarantine strategy, the rate of viral transmission has been slowed down, but there is still an urgent need to find a therapeutic agent to treat or prevent the transmission of the virus, especially in the light of possible reinfection after recovery (Alizargar, 2020; J. Huang et al., preprint, DOI: https://doi.org/10.1101/2020.05.06.20089573). The antibody-based vaccines against viral surface spike proteins are under development to prevent viral entry into the cells (M. A. Mong et al., preprint, DOI: https://doi.org/10. 1101/2020.04.19.20071647; Omer et al., 2020; Ota, 2020; Xu et al., 2020). Though the production of an efficient vaccine is still in progress, other treatments and prophylaxis approaches seem necessary. In this paper, we propose using HBPs (Wall et al., 2011, 2012, 2013a, 2015, 2017, 2019; Martin et al., 2013, 2014, 2016; Kennel et al., 2016a; Stuckey et al., 2020), which also targets viral entry (Dogra et al., 2015; Pitt et al., 2016; Jackson et al., 2019). These peptides showed promising results in stopping the cellular entry of herpes virus in vitro (Dogra et al., 2015; Pitt et al., 2016; Jackson et al., 2019). The only limitation of this peptide therapy is that in in vivo studies, they didn't show strong antiviral activity to prevent infection
(Pitt et al., 2016; Jackson et al., 2019). These peptides just target the first stage of infection, which is the HSPGdependent viral internalization, and are not efficient in targeting cytoplasmic viruses, which already escaped the endosomal pathway and are prone to enter nucleus for viral replication or exit cells to trigger the cell-to-cell transmission of infection (Greber and Way, 2006; Xiao and Samulski, 2012; Staring et al., 2018). This might be because these peptides are taken up by cells via HSPG-mediated endocytosis and enter the endosomal-lysosomal system to be degraded (Fig. 2B). Thus, they are not able to escape the endosomal pathway and cannot sufficiently target viral particles in the cytoplasm (Fig. 2A). Therefore, despite the initial inhibitory effect to reduce the level of viral uptake, the number of cytoplasmic viruses increases, and subsequently, the infection spreads throughout the body. To overcome this limitation, we suggest conjugation of these peptides with a carrier protein, CRM-197, which itself is an HBP (Gaillard et al., 2005; De Boer and Gaillard, 2007; Kakimoto et al., 2009; Shinefield, 2010; Wang et al., 2011; Malito et al., 2012).

This common vaccine carrier protein hijacks its cellular receptor, pro-HB-EGF, to internalize cells and enhance the transport and distribution of conjugated therapies within the cells by induction of endosomal escape of HPB (Giannini et al., 1984; De Boer and Gaillard, 2007; Kakimoto et al., 2009; Wang et al, 2011; Malito et al., 2012; Möginger et al., 2016). Thus, conjugates of the HBPs with CRM-197 (HBP-CRM-197) will be able to escape the endosomal pathway and enter cytoplasm to target cytoplasmic viruses (Fig. 2C). Binding of HBP-CRM197 to cytoplasmic viruses antagonizes viral replication and/or cell-to-cell transmission. This engineered peptide conjugate possesses full target engagement and potentially can be useful in both prophylactic therapies to prevent viral infection (cellular entrance) and therapeutic therapy to treat the infected person (stopping infection spread). Furthermore, molecular interaction modeling also shows favorable interactions between SARS-CoV-2 spike protein $\mathrm{S} 1$ and these HBPs (P5 + 14 and CRM-197), and it suggests that conjugation of these peptides might increase the binding affinity to spike protein S1 (Fig. 3). This engineered peptide can also be used as a PET imaging agent to detect intracellular fibrils of proteins in the brain, which are hallmarks of neurodegenerative diseases.

\section{Authorship Contributions}

Wrote or contributed to the writing of the manuscript: O. Tavassoly, Safavi, I. Tavassoly.

\section{References}

Alizargar J (2020) Risk of reactivation or reinfection of novel coronavirus (COVID19). J Formos Med Assoc 119:1123.

Beierle SP, Foster JS, Richey T, Stuckey A, Macy S, Kennel SJ, and Wall JS (2017) A novel murine system for validating the specific targeting of peptides to light chain associated (AL) amyloid. Amyloid 24:74-75.

Blancas-Mejía LM, Hammernik J, Marin-Argany M, and Ramirez-Alvarado M (2015) Differential effects on light chain amyloid formation depend on mutations and type of glycosaminoglycans. J Biol Chem 290:4953-4965.

Bourgault S, Solomon JP, Reixach N, and Kelly JW (2011) Sulfated glycosaminoglycans accelerate transthyretin amyloidogenesis by quaternary structural conversion. Biochemistry 50:1001-1015.

Buck CB, Day PM, and Trus BL (2013) The papillomavirus major capsid protein L1. Virology 445:169-174.

Cagno V, Donalisio M, Civra A, Volante M, Veccelli E, Oreste P, Rusnati M, and Lembo D (2014) Highly sulfated K5 Escherichia coli polysaccharide derivatives inhibit respiratory syncytial virus infectivity in cell lines and human trachealbronchial histocultures. Antimicrob Agents Chemother 58:4782-4794.

Christianson HC and Belting M (2014) Heparan sulfate proteoglycan as a cell-surface endocytosis receptor. Matrix Biol 35:51-55. 
Compton T, Nowlin DM, and Cooper NR (1993) Initiation of human cytomegalovirus infection requires initial interaction with cell surface heparan sulfate. Virology 193:834-841.

Connors JM and Levy JH (2020) COVID-19 and its implications for thrombosis and anticoagulation. Blood 135:2033-2040.

Crowther MA and Warkentin TE (2008) Bleeding risk and the management of bleeding complications in patients undergoing anticoagulant therapy: focus on new anticoagulant agents. Blood 111:4871-4879.

de Boer AG and Gaillard PJ (2007) Strategies to improve drug delivery across the blood-brain barrier. Clin Pharmacokinet 46:553-576.

de Haan CA, Haijema BJ, Schellen P, Wichgers Schreur P, te Lintelo E, Vennema H, and Rottier PJ (2008) Cleavage of group 1 coronavirus spike proteins: how furin cleavage is traded off against heparan sulfate binding upon cell culture adaptation. $J$ Virol 82:6078-6083.

Dogra P, Martin EB, Williams A, Richardson RL, Foster JS, Hackenback N, Kenne SJ, Sparer TE, and Wall JS (2015) Novel heparan sulfate-binding peptides for blocking herpesvirus entry. PLoS One 10:e0126239.

Donalisio M, Rusnati M, Cagno V, Civra A, Bugatti A, Giuliani A, Pirri G, Volante M, Papotti M, Landolfo S, et al. (2012) Inhibition of human respiratory syncytial virus infectivity by a dendrimeric heparan sulfate-binding peptide. Antimicrob Agents Chemother 56:5278-5288.

Gaillard PJ, Brink A, and De Boer AG (2005) Diphtheria toxin receptor-targeted brain drug delivery. Int Congr Ser 1277:185-198.

Gaviglio AL, Knelson EH, and Blobe GC (2017) Heparin-binding epidermal growth factor-like growth factor promotes neuroblastoma differentiation. FASEB $J \mathbf{3 1}$ 1903-1915.

Ghezzi S, Cooper L, Rubio A, Pagani I, Capobianchi MR, Ippolito G, Pelletier J, Meneghetti MCZ, Lima MA, Skidmore MA, et al. (2017) Heparin prevents Zika virus induced-cytopathic effects in human neural progenitor cells. Antiviral Res 140:13-17.

Giannini G, Rappuoli R, and Ratti G (1984) The amino-acid sequence of two non-toxic mutants of diphtheria toxin: CRM45 and CRM197. Nucleic Acids Res 12 $4063-4069$

Giroglou T, Florin L, Schäfer F, Streeck RE, and Sapp M (2001) Human papillomavirus infection requires cell surface heparan sulfate. J Virol 75:1565-1570.

Greber UF and Way M (2006) A superhighway to virus infection. Cell 124:741-754.

Hirsh J, Anand SS, Halperin JL, and Fuster V; American Heart Association (2001) Guide to anticoagulant therapy: heparin: a statement for healthcare professionals from the American Heart Association, Circulation 103, pp 2994-3018.

Holmes BB, DeVos SL, Kfoury N, Li M, Jacks R, Yanamandra K, Ouidja MO, Brodsky FM, Marasa J, Bagchi DP, et al. (2013) Heparan sulfate proteoglycans mediate internalization and propagation of specific proteopathic seeds. Proc Nat Acad Sci USA 110:E3138-E3147.

Horonchik L, Tzaban S, Ben-Zaken O, Yedidia Y, Rouvinski A, Papy-Garcia D, Barritault D, Vlodavsky I, and Taraboulos A (2005) Heparan sulfate is a cellular receptor for purified infectious prions. J Biol Chem 280:17062-17067.

Huang X, Pearce R, and Zhang Y (2020) De novo design of protein peptides to block association of the SARS-CoV-2 spike protein with human ACE2. Aging (Albany NY) 12:11263-11276.

Hudák A, Kusz E, Domonkos I, Jósvay K, Kodamullil AT, Szilák L, Hofmann-Apitius M, and Letoha T (2019) Contribution of syndecans to cellular uptake and fibrillation of $\alpha$-synuclein and tau. Sci Rep 9:16543.

Jackson JW, Hancock TJ, Dogra P, Patel R, Arav-Boger R, Williams AD, Kennel SJ, Wall JS, and Sparer TE (2019) Anticytomegalovirus peptides point to new insights for CMV entry mechanisms and the limitations of in vitro screenings. mSphere 4 e00586-18.

Johnson SM, McNally BA, Ioannidis I, Flano E, Teng MN, Oomens AG, Walsh EE, and Peeples ME (2015) Respiratory syncytial virus uses CX3CR1 as a receptor on primary human airway epithelial cultures. PLoS Pathog 11:e1005318.

Kakimoto S, Hamada T, Komatsu Y, Takagi M, Tanabe T, Azuma H, Shinkai S, and Nagasaki T (2009) The conjugation of diphtheria toxin T domain to poly(ethylenimine) based vectors for enhanced endosomal escape during gene transfection. Biomaterials 30:402-408.

Kennel SJ, Stuckey A, McWilliams-Koeppen HP, Richey T, and Wall JS (2016a) Tc$99 \mathrm{~m}$ radiolabeled peptide $\mathrm{p} 5+14$ is an effective probe for SPECT imaging of systemic amyloidosis. Mol Imaging Biol 18:483-489.

Kennel SJ, Williams A, Stuckey A, Richey T, Wooliver C, Chazin W, Stern DA, Martin EB, and Wall JS (2016b) The pattern recognition reagents RAGE VC1 and peptide p5 share common binding sites and exhibit specific reactivity with AA amyloid in mice. Amyloid 23:8-16.

Kim SY, Zhao J, Liu X, Fraser K, Lin L, Zhang X, Zhang F, Dordick JS, and Linhardt RJ (2017) Interaction of Zika virus envelope protein with glycosaminoglycans. Biochemistry 56:1151-1162.

Knittel D, Savatier A, Upert G, Lortat-Jacob H, and Léonetti M (2015) Acidosis increases MHC class II-restricted presentation of a protein endowed with a pHdependent heparan sulfate-binding ability. J Immunol 194:3601-3611.

Langer F, Kluge S, Klamroth R, and Oldenburg J (2020) Coagulopathy in COVID-19 and its implication for safe and efficacious thromboprophylaxis. Hamostaseologie 40:264-269.

Leistner CM, Gruen-Bernhard S, and Glebe D (2008) Role of glycosaminoglycans for binding and infection of hepatitis B virus. Cell Microbiol 10:122-133.

Lu J, Yu Y, Zhu I, Cheng Y, and Sun PD (2014) Structural mechanism of serum amyloid A-mediated inflammatory amyloidosis. Proc Natl Acad Sci USA 111 $5189-5194$

Luk KC, Kehm V, Carroll J, Zhang B, O'Brien P, Trojanowski JQ, and Lee VM (2012a) Pathological $\alpha$-synuclein transmission initiates Parkinson-like neurodegeneration in nontransgenic mice. Science 338:949-953.

Luk KC, Kehm VM, Zhang B, O'Brien P, Trojanowski JQ, and Lee VM (2012b) Intracerebral inoculation of pathological $\alpha$-synuclein initiates a rapidly progressive neurodegenerative $\alpha$-synucleinopathy in mice. J Exp Med 209:975-986.
Malito E, Bursulaya B, Chen C, Lo Surdo P, Picchianti M, Balducci E, Biancucci M, Brock A, Berti F, Bottomley MJ, et al. (2012) Structural basis for lack of toxicity of the diphtheria toxin mutant CRM197. Proc Natl Acad Sci USA 109 5229-5234.

Martin DJ and Ramirez-Alvarado M (2011) Glycosaminoglycans promote fibril formation by amyloidogenic immunoglobulin light chains through a transient interaction. Biophys Chem 158:81-89.

Martin EB, Kennel SJ, Richey T, Wooliver C, Osborne D, Williams A, Stuckey A and Wall JS (2014) Dynamic PET and SPECT imaging with radioiodinated, amyloid-reactive peptide p5 in mice: a positive role for peptide dehalogenation. Peptides 60:63-70.

Martin EB, Williams A, Heidel E, Macy S, Kennel SJ, and Wall JS (2013) Peptide p5 binds both heparinase-sensitive glycosaminoglycans and fibrils in patient-derived AL amyloid extracts. Biochem Biophys Res Commun 436:85-89.

Martin EB, Williams A, Richey T, Stuckey A, Heidel RE, Kennel SJ, and Wall JS (2016) Comparative evaluation of $\mathrm{p} 5+14$ with SAP and peptide p5 by dual-energy SPECT imaging of mice with AA amyloidosis. Sci Rep 6:22695.

Milewska A, Zarebski M, Nowak P, Stozek K, Potempa J, and Pyrc K (2014) Human coronavirus NL63 utilizes heparan sulfate proteoglycans for attachment to target cells. J Virol 88:13221-13230.

Mishra RPN, Yadav RSP, Jones C, Nocadello S, Minasov G, Shuvalova LA, Anderson WF, and Goel A (2018) Structural and immunological characterization of E. coli derived recombinant CRM $_{197}$ protein used as carrier in conjugate vaccines. Biosci Rep 38:BSR20180238.

Möginger U, Resemann A, Martin CE, Parameswarappa S, Govindan S, Wamhoff E-C, Broecker F, Suckau D, Pereira CL, Anish C, et al. (2016) Cross reactive material 197 glycoconjugate vaccines contain privileged conjugation sites. Sci Rep 6:20488.

Murando F, Peloso A, and Cobianchi L (2019) Experimental abdominal sepsis: sticking to an awkward but still useful translational model. Mediators Inflamm 2019:8971036

Mustard D and Ritchie DW (2005) Docking essential dynamics eigenstructures. Proteins 60:269-274.

Nishida O, Ogura H, Egi M, Fujishima S, Hayashi Y, Iba T, Imaizumi H, Inoue S, Kakihana Y, Kotani J, et al. (2018) The Japanese clinical practice guidelines for management of sepsis and septic shock 2016 (J-SSCG 2016). J Intensive Care 6:7.

Noborn F, Ancsin JB, Ubhayasekera W, Kisilevsky R, and Li JP (2012) Heparan sulfate dissociates serum amyloid A (SAA) from acute-phase high-density lipoprotein, promoting SAA aggregation. $J$ Biol Chem 287:25669-25677.

Noborn F, O'Callaghan P, Hermansson E, Zhang X, Ancsin JB, Damas AM, Dacklin I, Presto J, Johansson J, Saraiva MJ, et al. (2011) Heparan sulfate/heparin promotes transthyretin fibrillization through selective binding to a basic motif in the protein. Proc Natl Acad Sci USA 108:5584-5589.

Omer SB, Malani P, and Del Rio C (2020) The COVID-19 pandemic in the US: a clinical update. JAMA DOI: 10.1001/jama.2020.5788 [published ahead of print]. Ota M (2020) Will we see protection or reinfection in COVID-19? Nat Rev Immunol 20:351.

Pitt EA, Dogra P, Patel RS, Williams A, Wall JS, and Sparer TE (2016) The D-form of a novel heparan binding peptide decreases cytomegalovirus infection in vivo and in vitro. Antiviral Res 135:15-23

Rauch JN, Chen JJ, Sorum AW, Miller GM, Sharf T, See SK, Hsieh, Wilson LC, Kampmann M, and Kosik KS (2018) Tau internalization is regulated by 6-O sulfation on heparan sulfate proteoglycans (HSPGs). Sci Rep 8:6382.

Ritchie DW (2003) Evaluation of protein docking predictions using Hex 3.1 in CAPRI rounds 1 and 2. Proteins 52:98-106.

Sandwall E, O'Callaghan P, Zhang X, Lindahl U, Lannfelt L, and Li JP (2010) Heparan sulfate mediates amyloid-beta internalization and cytotoxicity. Glycobiology 20:533-541.

Sarrazin S, Lamanna WC, and Esko JD (2011) Heparan sulfate proteoglycans. Cold Spring Harb Perspect Biol 3:a004952.

Schonberger O, Horonchik L, Gabizon R, Papy-Garcia D, Barritault D, and Taraboulos A (2003) Novel heparan mimetics potently inhibit the scrapie prion protein and its endocytosis. Biochem Biophys Res Commun 312:473-479.

Shinefield HR (2010) Overview of the development and current use of CRM(197) conjugate vaccines for pediatric use. Vaccine 28:4335-4339.

Staring J, Raaben M, and Brummelkamp TR (2018) Viral escape from endosomes and host detection at a glance. J Cell Sci 131:jcs216259.

Stuckey A, Martin E, Powell D, Fu Y, Besozzi M, Hall S, Kennel S, and Wall J (2020) Time resolved biodistribution of peptide 124I-p5+14 in patients with systemic AL amyloidosis. J Nucl Med 61:3127.

Tan CW, Sam IC, Chong WL, Lee VS, and Chan YF (2017) Polysulfonate suramin inhibits Zika virus infection. Antiviral Res 143:186-194.

Tang N, Bai H, Chen X, Gong J, Li D, and Sun Z (2020) Anticoagulant treatment is associated with decreased mortality in severe coronavirus disease 2019 patients with coagulopathy. $J$ Thromb Haemost 18:1094-1099.

Tavassoly O, Sade D, Bera S, Shaham-Niv S, Vocadlo DJ, and Gazit E (2018) Quinolinic acid amyloid-like fibrillar assemblies seed $\alpha$-synuclein aggregation. $J \mathrm{Mol}$ Biol 430:3847-3862.

Tavassoly O, Yue J, and Vocadlo DJ (2020) Pharmacological inhibition and knockdown of O-GlcNAcase reduces cellular internalization of $\alpha$-synuclein preformed fibrils. FEBS J DOI: 10.1111/febs.15349 [published ahead of print].

The Lancet Haematology (2020) COVID-19 coagulopathy: an evolving story. Lancet Haematol 7:e425.

Umemura Y, Yamakawa K, Ogura H, Yuhara H, and Fujimi S (2016) Efficacy and safety of anticoagulant therapy in three specific populations with sepsis: a metaanalysis of randomized controlled trials. J Thromb Haemost 14:518-530.

Wall JS, Kennel SJ, and Martin EB (2017) Dual-energy SPECT and the development of peptide p5+14 for imaging amyloidosis. Mol Imaging 16:1536012117708705.

Wall JS, Martin EB, Richey T, Stuckey AC, Macy S, Wooliver C, Williams A, Foster JS, McWilliams-Koeppen P, Uberbacher E, et al. (2015) Preclinical validation of 
the heparin-reactive peptide p5+14 as a molecular imaging agent for visceral amyloidosis. Molecules 20:7657-7682.

Wall JS, Richey T, Macy S, Heidel E, Wooliver C, and Kennel SJ (2013a) A novel method for quantifying peripheral tissue amyloid load by using the radiolabeled amyloidophilic peptide, p5. Amyloid 20:21-26.

Wall JS, Richey T, Stuckey A, Donnell R, Macy S, Martin EB, Williams A, Higuchi K, and Kennel SJ (2011) In vivo molecular imaging of peripheral amyloidosis using heparin-binding peptides. Proc Natl Acad Sci USA 108:E586-E594.

Wall JS, Richey T, Williams A, Stuckey A, Osborne D, Martin E, and Kennel SJ (2012) Comparative analysis of peptide p5 and serum amyloid P component for imaging AA amyloid in mice using dual-isotope SPECT. Mol Imaging Biol 14: 402-407.

Wall JS, Stuckey A, Martin EB, Richey T, Williams A, Wooliver DC, Macy S, Foster JS, Whittle B, Geldrich R, et al. (2019) Preliminary phase 1 data on the safety and efficacy of a novel PET radiotracer, 124I-p5+14, for imaging systemic amyloidosis. Blood 134:3034.

Wall JS, Williams A, Richey T, Stuckey A, Huang Y, Wooliver C, Macy S, Heidel E, Gupta N, Lee A, et al. (2013b) A binding-site barrier affects imaging efficiency of high affinity amyloid-reactive peptide radiotracers in vivo. PLoS One 8:e66181.

Wang P, Liu Y, Shang X, and Xue Y (2011) CRM197-induced blood-brain barrier permeability increase is mediated by upregulation of caveolin-1 protein. $J$ Mol Neurosci 43:485-492.

Waterhouse A, Bertoni M, Bienert S, Studer G, Tauriello G, Gumienny R, Heer FT, de Beer TAP, Rempfer C, Bordoli L, et al. (2018) SWISS-MODEL: homology modelling of protein structures and complexes. Nucleic Acids Res 46:W296-W303.
Xiao P-J and Samulski RJ (2012) Cytoplasmic trafficking, endosomal escape, and perinuclear accumulation of adeno-associated virus type 2 particles are facilitated by microtubule network. $J$ Virol 86:10462-10473.

Xu Y, Martinez P, Séron K, Luo G, Allain F, Dubuisson J, and Belouzard S (2015) Characterization of hepatitis $\mathrm{C}$ virus interaction with heparan sulfate proteoglycans. J Virol 89:3846-3858.

Xu Z, Shi L, Wang Y, Zhang J, Huang L, Zhang C, Liu S, Zhao P, Liu H, Zhu L, et al. (2020) Pathological findings of COVID-19 associated with acute respiratory distress syndrome. Lancet Respir Med 8:420-422.

Yan Y, Tao H, He J, and Huang S-Y (2020) The HDOCK server for integrated protein-protein docking. Nat Protoc 15:1829-1852.

Zhang C, Zheng W, Huang X, Bell EW, Zhou X, and Zhang Y (2020) Protein structure and sequence reanalysis of $2019-\mathrm{nCoV}$ genome refutes snakes as its intermediate host and the unique similarity between its spike protein insertions and HIV-1. $J$ Proteome Res 19:1351-1360.

Zhou Y, Wang Y, Olson J, Yang J, and Besner GE (2017) Heparin-binding EGF-like growth factor promotes neuronal nitric oxide synthase expression and protects the enteric nervous system after necrotizing enterocolitis. Pediatr Res 82:490-500.

Address correspondence to: Dr. Iman Tavassoly, C2i Genomics, 180 Varick St., 6th Fl., New York, NY 10014. E-mail: tavassoly@gmail.com; or Dr. Omid Tavassoly, Department of Chemistry, Simon Fraser University, Burnaby, BC, Canada V5A 1S6. E-mail: otavasso@sfu.ca 